
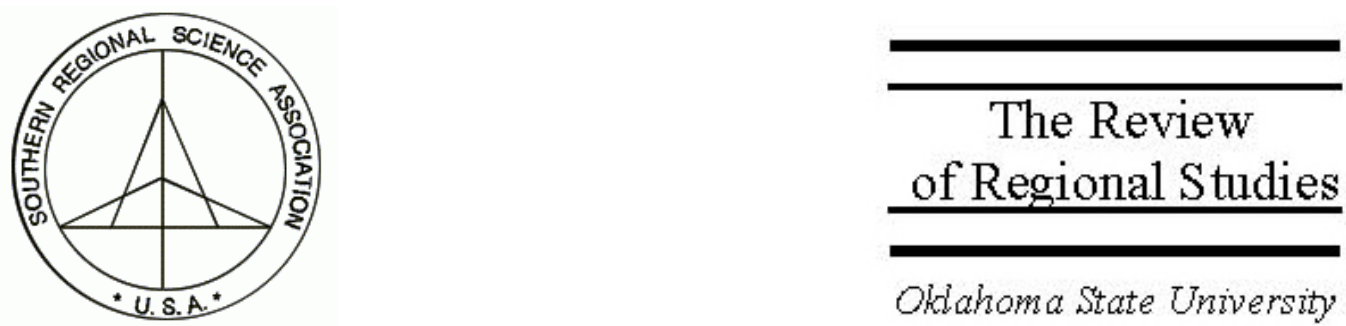

\title{
Explaining Per Capita Personal Income Differences between States
}

\author{
John E. Connaughton \\ Department of Economics, University of North Carolina at Charlotte, 9201 University \\ City Boulevard, Charlotte, NC 28223, e-mail: jec@email.uncc.edu \\ Ronald A. Madsen \\ Department of Economics, University of North Carolina at Charlotte, 9201 University \\ City Boulevard, Charlotte, NC 28223, e-mail: ramadsen@email.uncc.edu
}

\begin{abstract}
The purpose of this paper is to identify factors that explain the differences in state PCPI levels and to examine the question of how demographic factors have influenced changes in state PCPI levels over the census years between 1950 and 2000. The results suggest that the racial composition of state populations has had little influence on state real PCPI levels. The important variables in explaining real PCPI differences between the states appear to be the percentage of the population that lives in urban areas, the percentage of the population with a four-year college degree, and the percentage of the population employed in the service sector.
\end{abstract}

Keywords: State PCPI; Regional PCPI; PCPI impact of college education; Impact of urbanization on state PCPI

JEL classification: R10; R11 


\section{INTRODUCTION}

Since World War II, regional economic development in the United States has shown patterns of variation over time. This variation in development has occurred both by region and by state. The sources of these differences are of major interest to economists and planners concerned with regional economic development and growth. Accordingly, there have been numerous attempts to address the question of how and why economic performance varies by state. The purpose of this paper is to identify factors that explain the levels of and differences in state per capita personal income (PCPI) and to examine the question of how the influence of these factors has changed over time. PCPI as a measure of performance is common to much of the literature in this area of research and has been measured in a consistent manner over a reasonably long period of time. This study covers the time period between 1950 and 2000 and utilizes state-level decennial census information to empirically address the research questions.

\section{LITERATURE REVIEW}

There are a number of explanatory variables that are consistently identified as having an influence on state economic performance. Vohra (1997) specifies differences in the gender composition of the labor force, differences in industrial mix, differences in human capital, and differences in technology or physical capital to explain forces influencing productivity and the rate of convergence among states. His work builds on earlier work by Barro and Sala-I-Martin (1992) at the state level. Vohra's findings, covering the period 1969-1988, indicate convergence in state productivity performance and suggest that human capital and composition of the labor force are the most important explanatory variables (Vohra 1997, p. 413). He further identifies a decreasing role for manufacturing and an increasing role in service employment in explaining state performance over time. This result is consistent with Gamick's (1990) findings that industry mix contributed less to PCPI convergence in the 1970s and 1980s than during the overall period between 1940 and 1979 (Gamick 1990, pp. 30-31).

Dealing with a related topic of changes in income inequality, measured by gini coefficients, Levernier, Rickman, and Partridge (1995) utilize cross sectional data from 1960, 1970, 1980, and 1990 to show a convergence of state income inequality over these time periods. Their approach utilized economic, demographic, human capital, and labor market variables along with regional dummies to capture unmeasured regional fixed effects (Levernier, Rickman, and Partridge 1995, pp. 363-364).

Berry and Kaserman (1993) developed a diffusion model of long-run state economic development and produced results generally confirming the convergence of state PCPI over time. They found low taxes and strong support for higher education to be major factors in explaining variation in state economic growth over the extended time period of 1929-1987. Berry and Kaserman (1993) also included as an explanatory variable the percentage of employment in manufacturing. This variable tested significant at the 95 percent level of confidence. Further, Mallick (1993) and Bound and Johnson (1992) 
found a decreasing role for gender differences and an increasing role for differences in human capital (education) in explaining differences in state PCPI levels in the 1980s.

An ongoing question dealing with the impact of the racial composition of state populations on state PCPI levels seems to be less well developed. For the most part, the impact of the racial composition has focused on the intra-state and intra-region income dispersion (Nissan and Carter (2003), not the level of state PCPI. Most studies adhere to the common perception that there is a negative correlation between the percentage of the population that is black and per capita income levels. However, Sowell (2000) points out that a recent Census Bureau study of incomes in the United States reports, in one brief sentence, that between 1989 and 1999 the real per capita income of whites rose 13 percent while the real per capita income of blacks rose 24 percent. Sowell (2000) rejects the common perception that there is a negative correlation between the percentage of the population that is black and per capita income levels. In addition, Izraeli and Murphy (1997), in an article on convergence of state PCPI, include a non-white population variable that proves to be negative and "weakly significant." Since the racial composition of state populations varies significantly, the impact of this demographic difference may be important in explaining differences in state PCPI levels, but it is not clear whether the impact is negative, neutral, or positive.

\section{MODEL SPECIFICATIONS AND DATA}

The model specified for this study explains state real PCPI levels as a function of a set of demographic, human capital, industrial structure variables, and a set of regional dummy variables to capture regional fixed effects. The same model is estimated for each of the years 1950, 1960, 1970, 1980, 1990, and 2000. The results will allow for the identification of significant relationships in each year and will also allow for comparisons of the changing influence of these factors over time. The model is specified as:

$$
\begin{aligned}
& \text { RPCPI }_{i}=\text { B }_{0}+\text { B }_{1} \text { PCTBLACK }_{i}+\text { B }_{2} \text { PCTURBAN }_{i}+\text { B }_{3} \text { PCTHS }_{\mathrm{i}}+\text { B }_{4} \text { PCTCOL }_{i} \\
& + \text { B }_{5} \text { PCTMFG }_{i}+\text { B }_{6} \text { PCTSER }_{\mathrm{i}}+\text { B }_{7} \text { DME }_{\mathrm{i}}+\text { B }_{8} \text { DGL }_{\mathrm{i}}+\text { B }_{9} \text { DP }_{\mathrm{i}}+\mathrm{B}_{10} \mathrm{DSE}_{\mathrm{i}}+\mathrm{B}_{11} \mathrm{DSW}_{\mathrm{i}} \\
& +\mathrm{B}_{12} \mathrm{DRM}_{\mathrm{i}}+\mathrm{B}_{13} \mathrm{DFW}_{\mathrm{i}}+\mathrm{E}_{\mathrm{i}}
\end{aligned}
$$

where:

$\mathrm{RPCPI}_{\mathrm{i}}=$ Real Per Capita Personal Income in state $\mathrm{i}$ in the given census year in year 2000 dollars;

PCTBLACK $_{i}=$ the percent of the population of state $\mathrm{i}$ that was classified African American in the given census year;

PCTURBAN $_{\mathrm{i}}=$ the percent of the population of state $\mathrm{i}$ that was classified urban in the given census year; 
PCTHS $_{\mathrm{i}}=$ the percent of the adult population of state $\mathrm{i}$ in the given census year that had a high school education;

PCTCOL $_{i}=$ the percent of the adult population of state $i$ in the given census year that had a four-year college education;

$\mathrm{PCTMFG}_{\mathrm{i}}=$ the percent of the population of state $\mathrm{i}$ in the given census year that was employed in the manufacturing sector;

PCTSER $_{\mathrm{i}}=$ the percent of the population of state $\mathrm{i}$ in the given census year that was employed in the service sector;

$\mathrm{DME}_{\mathrm{i}}=$ a regional dummy with a value of 1 if the state is in the Mid-East BEA region and 0 otherwise (see Appendix Table A-3 for the location of states by BEA region);

$\mathrm{DGL}_{\mathrm{i}}=$ a regional dummy with a value of 1 if the state is in the Great Lakes BEA region and 0 otherwise;

$\mathrm{DP}_{\mathrm{i}}=$ a regional dummy with a value of 1 if the state is in the Plains BEA region and 0 otherwise;

$\mathrm{DSE}_{\mathrm{i}}=$ a regional dummy with a value of 1 if the state is in the South-East BEA region and 0 otherwise;

$\mathrm{DSW}_{\mathrm{i}}=$ a regional dummy with a value of 1 if the state is in the South-West BEA region and 0 otherwise;

$\mathrm{DRM}_{\mathrm{i}}=$ a regional dummy with a value of 1 if the state is in the Rocky Mountain BEA region and 0 otherwise;

$\mathrm{DFW}_{\mathrm{i}}=$ a regional dummy with a value of 1 if the state is in the Far-West BEA region and 0 otherwise.

Real per capita personal income (RPCPI) was used as the dependent variable to allow for more direct comparisons of the magnitude of coefficients on the independent variables across census years. The choice of year 2000 dollars was made to allow the most current frame of reference for the reader in understanding the magnitudes of the estimated coefficients and to be able to better understand how these coefficients may have changed over time. The transformation to year 2000 values was made using the $\mathrm{CPI}-\mathrm{U}$ values for the given census year. (The tests of significance and $\mathrm{R}^{2}$ values for each census year are not impacted by these scalar transformations.)

The PCTBLACK variable is included to control for the differences in RPCPI that may be related to the racial differences between the states. The sign on this coefficient is not predicted. PCTURBAN is included to reflect the differences between the state levels of RPCPI that are related to the degree of urban concentration. The sign on this coefficient is expected to be positive, based on the fuller range of job opportunities typically available in urban areas and the historical movement of rural populations to urban areas to find better paying jobs. The variables for education, PCTHS and PCTCOL, are 
included as a measure of human capital and are expected to have positive coefficients. The inclusion of both variables can help address the question of the relative importance of higher education versus a standard high school education on explaining differences in state RPCPI levels. The two industry structure variables, PCTMFG and PCTSER, were included to measure the influence of these important sectors on differences in state RPCPI levels, and the changes in the coefficients of these variables over the different census years may shed light on Vohra's (1997) earlier work. The signs on these coefficients were not predicted since there are elements of each that could lead to either positive or negative influences on RPCPI levels.

The regional variables were included to capture regional fixed effects. The eight Bureau of Economic Analysis regions were used in this study. (The list of states in each of these regions is provided in Appendix Table A-1.) The coefficients on the seven regional dummy variables are interpreted as the difference in RPCPI for states in the specified region versus the RPCPI of states located in the New England BEA region (the omitted regional category) after controlling for the other variables in the model. No prediction of the signs on these regional coefficients was made.

The data for this study was taken from the state census reports for the census years 1950, 1960, 1970, 1980, 1990, and 2000. The OLS regression estimates for each of these years are reported in Table 1 in the following section. White's test for heteroskedasticity was conducted for each of these estimates, and the results of White's tests are reported in Appendix Table A.2. Where appropriate, the t-statistics reported in Table 1 are based on robust errors calculated using White's correction for heteroskedasticity. Additionally, the model was estimated using the pooled cross sectional data for all the census years to look for results that might differ in significant ways from the results and patterns reflected in the individual census year results. The results for the pooled results are reported in Table 2.

\section{RESULTS}

The regression results provided in Table 1 for census year 1950 show a generally good fit for the equation as a whole. The $\mathrm{R}^{2}$ value is .874 , and the F-statistic is 18.205. Further, three of the six coefficients on the demographic, human capital, industrial structure variables test statistically significant at the .10 level or above while the signs on PCTURBAN, PCTHS, and PCTCOL are positive as predicted. The small negative coefficient on PCTBLACK is not significant and suggests there were no systematic differences in 1950 state RPCPI levels associated with this measure, ceteris paribus. The coefficient on PCTURBAN suggests that for each one percent increase in the urban population of a state in 1950, the state RPCPI level increased by $\$ 33.76$, ceteris paribus. This result indicates an elasticity of .332 percent when evaluated at the point of means. (Elasticities for all coefficient and all equations are presented in the Appendix in Table A-3.) The coefficient on PCTHS is positive as expected but not significant. The coefficient on PCTCOL indicates that for each one percent increase in the state's percentage of college graduates, the RPCPI of the state increased \$64.82; and it tests significant, ceteris 
TABLE 1

OLS Regression Results: Dependent Variable Real Per Capita Personal Income in Base Year 2000 Dollars

\begin{tabular}{|c|c|c|c|c|c|c|}
\hline \multirow[b]{2}{*}{ Variable } & \multicolumn{6}{|c|}{ Census Year } \\
\hline & 1950 & 1960 & 1970 & 1980 & 1990 & 2000 \\
\hline CONSTANT & $1,956.72$ & $4,441.49$ & $8,402.00$ & $4,436.68$ & $3,817.55$ & $4,786.13$ \\
\hline PCTBLACK & $\begin{array}{c}-32.15 \\
(1.268)\end{array}$ & $\begin{array}{c}-30.74 \\
(1.437)\end{array}$ & $\begin{array}{r}-31.04 \\
(.886)\end{array}$ & $\begin{array}{r}40.15 \\
(.710)\end{array}$ & $\begin{array}{r}-7.07 \\
(.139)\end{array}$ & $\begin{array}{r}13.59 \\
(.219)\end{array}$ \\
\hline PCTURBAN & $\begin{array}{l}33.76^{*} \\
(1.804)\end{array}$ & $\begin{array}{l}10.59 \\
(.501)\end{array}$ & $\begin{array}{l}45.21^{* *} \\
(2.474)\end{array}$ & $\begin{array}{l}40.68 \\
(1.600)\end{array}$ & $\begin{array}{l}91.92^{* *} \\
(3.717)\end{array}$ & $\begin{array}{r}115.20^{* *} \\
(2.226)\end{array}$ \\
\hline PCTHS & $\begin{array}{l}36.69 \\
(.309)\end{array}$ & $\begin{array}{l}63.98 \\
(.601)\end{array}$ & $\begin{array}{l}7.90 \\
(.073)\end{array}$ & $\begin{array}{r}308.30^{*} \\
(2.087)\end{array}$ & $\begin{array}{c}170.38 \\
(1.070)\end{array}$ & $\begin{array}{c}75.70 \\
(.310)\end{array}$ \\
\hline PCTCOL & $\begin{array}{l}64.82^{*} \\
(1.893)\end{array}$ & $\begin{array}{r}1,410.99^{* * *} \\
(4.140)\end{array}$ & $\begin{array}{r}1,051.51^{* *} \\
(4.065)\end{array}$ & $\begin{array}{r}891.45^{* *} \\
(3.782)\end{array}$ & $\begin{array}{r}1,200.49^{* * *} \\
(4.752)\end{array}$ & $\begin{array}{r}1,173.18^{* * *} \\
(3.379)\end{array}$ \\
\hline PCTMFG & $\begin{array}{l}119.30 \\
(1.306)\end{array}$ & $\begin{array}{c}49.06 \\
(.700)\end{array}$ & $\begin{array}{r}-39.00 \\
(.326)\end{array}$ & $\begin{array}{r}-117.20 \\
\quad(.715)\end{array}$ & $\begin{array}{r}-46.18 \\
(.352)\end{array}$ & $\begin{array}{l}130.66 \\
\quad .603)\end{array}$ \\
\hline PCTSER & $\begin{array}{r}575.13^{* *} \\
(2.731)\end{array}$ & $\begin{array}{r}75.18 \\
(.637)\end{array}$ & $\begin{array}{l}99.50 \\
(.379)\end{array}$ & $\begin{array}{r}-69.46 \\
(.281)\end{array}$ & $\begin{array}{r}197.65 \\
(.880)\end{array}$ & $\begin{array}{r}164.29 \\
\quad .640)\end{array}$ \\
\hline DME & $\begin{array}{r}2,312.44^{* *} \\
\quad(3.304)\end{array}$ & $\begin{array}{r}1,265.91^{*} \\
(2.101)\end{array}$ & $\begin{array}{r}1,215.09 \\
(1.623)\end{array}$ & $\begin{array}{r}990.29 \\
(.764)\end{array}$ & $\begin{array}{r}1,223.52 \\
\quad(.918)\end{array}$ & $\begin{array}{r}446.27 \\
\quad(.151)\end{array}$ \\
\hline DGL & $\begin{array}{r}1,808.25^{* *} \\
(2.897)\end{array}$ & $\begin{array}{r}1,579.03^{* *} \\
(2.933)\end{array}$ & $\begin{array}{r}1,161.90^{*} \\
(1.767)\end{array}$ & $\begin{array}{r}1,626.67 \\
(1.595)\end{array}$ & $\begin{array}{r}-222.64 \\
\quad(.165)\end{array}$ & $\begin{array}{r}-1,233.27 \\
\quad(.470)\end{array}$ \\
\hline DP & $\begin{array}{r}2,037.59^{* *} \\
(2.140)\end{array}$ & $\begin{array}{l}110.10 \\
\quad(.146)\end{array}$ & $\begin{array}{r}-826.33 \\
\quad(.859)\end{array}$ & $\begin{array}{r}-497.45 \\
(.395)\end{array}$ & $\begin{array}{r}-2,564.57^{* *} \\
(2.380)\end{array}$ & $\begin{array}{r}-2,635.93 \\
(1.460)\end{array}$ \\
\hline DSE & $\begin{array}{r}110.36 \\
(.095)\end{array}$ & $\begin{array}{r}-870.70 \\
(1.127)\end{array}$ & $\begin{array}{r}-1,310.59 \\
\quad(1.193)\end{array}$ & $\begin{array}{r}-462.27 \\
\quad(.286)\end{array}$ & $\begin{array}{r}-1,042.75 \\
(.692)\end{array}$ & $\begin{array}{r}-2,224.24 \\
(.860)\end{array}$ \\
\hline DSW & $\begin{array}{r}611.44 \\
\quad(.488)\end{array}$ & $\begin{array}{r}-1,487.36^{*} \\
(1.862)\end{array}$ & $\begin{array}{r}-2,988.14^{* *} \\
(2.429)\end{array}$ & $\begin{array}{r}-772.68 \\
\quad(.491)\end{array}$ & $\begin{array}{r}-4,224.08^{* *} \\
(2.725)\end{array}$ & $\begin{array}{r}-4,062.91 \\
(1.375)\end{array}$ \\
\hline DRM & $\begin{array}{c}1,751.54 \\
\quad(1.625)\end{array}$ & $\begin{array}{r}-800.70 \\
(.926)\end{array}$ & $\begin{array}{r}-2,318.72^{* *} \\
(1.701)\end{array}$ & $\begin{array}{r}-622.80 \\
(.370)\end{array}$ & $\begin{array}{r}-4,315.90^{* *} \\
(3.163)\end{array}$ & $\begin{array}{r}-3,981.27 \\
(1.589)\end{array}$ \\
\hline DFW & $\begin{array}{r}2,596.55^{* *} \\
(3.041)\end{array}$ & $\begin{array}{r}1,392.50 \\
(1.282) \\
\end{array}$ & $\begin{array}{r}1,220.46 \\
(.953)\end{array}$ & $\begin{array}{r}2,532.27 \\
(1.533) \\
\end{array}$ & $\begin{array}{r}-309.55 \\
(.242)\end{array}$ & $\begin{array}{r}-1,825.81 \\
(.694)\end{array}$ \\
\hline Sample size & 48 & 50 & 50 & 50 & 50 & 50 \\
\hline $\mathrm{R}^{2}$ & 0.874 & 0.888 & 0.850 & 0.749 & 0.869 & 0.816 \\
\hline $\begin{array}{l}\text { F statistic } \\
\text { Std. Error }\end{array}$ & 18.205 & 21.934 & 15.733 & 8.249 & 18.433 & 12.321 \\
\hline $\begin{array}{l}\text { Regression } \\
\text { Mean Dep. }\end{array}$ & $\$ 941$ & $\$ 954$ & $\$ 1,282$ & $\$ 1,828$ & $\$ 1,628$ & $\$ 2,206$ \\
\hline $\begin{array}{l}\text { Var. } \\
\text { Std. Dev. }\end{array}$ & $\$ 10,157$ & $\$ 12,421$ & $\$ 17,193$ & $\$ 20,461$ & $\$ 24,503$ & $\$ 28,336$ \\
\hline Dep. Var. & $\$ 2,259$ & $\$ 2,442$ & $\$ 2,840$ & $\$ 3,124$ & $\$ 3,862$ & $\$ 4,413$ \\
\hline
\end{tabular}


paribus. This result provides an elasticity of .638 percent evaluated at the point of means. The coefficient on PCTMFG is positive but not significant, and the coefficient on PCTSER is large (575.13), positive, and significant. Each of these coefficients can be compared to the mean state RPCPI in 1950 of $\$ 10,156.64$. All the estimated coefficients on the regional dummies for 1950 are positive; and the coefficients for DME, DGL, DP, and DFW test significant at the .05 level. These results suggest the depressed relative nature of the states in the New England BEA region in 1950, but also the importance of controlling for these fixed regional effects when estimating RPCPI.

The regression results for 1960 in Table 1 show some interesting differences versus the 1950 results. The overall explanatory power of the 1960 results is good with an $\mathrm{R}^{2}$ value of .888; but the only coefficient on the demographic, human capital, and industrial structure variables that tests significant at the .10 level or above is for PCTCOL. The estimated coefficient on PCTBLACK is negative, small, and does not test significant. The coefficient on PCTURBAN is positive, small, and does not test significant. The coefficient on the education variable PCTHS is positive and does not test significant.

Unlike the 1950 results, in the 1960 estimates the coefficient on PCTCOL is much larger than the coefficient on PCTHS (1410.99 versus 63.98). This result does not, however, show a decrease in the influence of a high school education explaining differences in state PCPI levels since the elasticity (again calculated at the point of means) increased for PCTHS from .361 in 1950 to .515 in 1960.

The results for 1970, 1980, 1990, and 2000 in Table 1 show $\mathrm{R}^{2}$ values are $.850, .749$, .869 , and .816 , respectively. The lower $\mathrm{R}^{2}$ value in 1980 may well reflect the economic difficulties of the country as a whole in that census year. Between 1965 and 1980 the U.S. labor force grew by an average annual rate of 2.7 percent. This rapid labor force growth occurred during this period as a result of the influx of baby boomers into the labor market and the increase in female labor force participation rates. These large labor force growth rates caused a shift in the nation's unemployment rate and an overall soft labor market. The soft labor market depressed wage rates and increased under-employment with an associated devaluation of education.

The results on the estimates for the coefficients estimated on PCTBLACK over the six decades covered in this study were small, and none of these estimated coefficients tested significant. This result suggests that, ceteris paribus, the influence of the PCTBLACK was not a factor in explaining differences in RPCPI. This neutral result is different than (weakly) significant negative impact reported earlier by Izraeli and Murphy (1997) but may be consistent with Sowell's (2000) analysis since the estimated coefficients , though not significant, are initially negative (for 1950 and 1960) and then become positive, though still not significant, for 1970, 1990, and 2000.

The estimated coefficient on PCTURBAN is positive and significant in the equations for 1970, 1990, and 2000. This result is consistent with expectations and the 1950 and 1960 results presented earlier. Urban areas offer a wider range of educational and job 
opportunities, and states with a higher concentration of urban population typically have higher RPCPI levels.

As was true for the 1950 and 1960 results, the coefficient on PCTHS is positive in the estimated equations for 1970, 1980, 1990, and 2000. Only the estimated coefficient for 1980 tests significant at the .10 level or above. In general, differences in high school education across states appear to have a weak positive impact on state RPCPI.

The results on PCTCOL suggest that higher education in the form of a four-year college degree plays a very important role in explaining differences in state RPCPI levels. The estimated coefficients on PCTCOL are large, positive, and statistically significant for all of the census years except 1950 (where the coefficient is small, positive, and significant). Between 1960 and 2000 these coefficients are 1410.99 in 1960, 1051.51 in 1970, 891.45 in 1980, 1200.49 in 1990, and 1173.18 in 2000. Each of these coefficients estimates the impact of a one point increase in the percentage of the state population with a four-year college degree on that states RPCPI. Since RPCPI for each year is measured in year 2000 dollars, this result shows how consistently important higher education has been in explaining differences in RPCPI since 1950 (where the estimated coefficient on PCTCOL was only 64.82). The importance of higher education suggested by these results is consistent with the findings of Berry and Kaserman (1993), Mallick (1993), and Bound and Johnson (1992) cited earlier.

The coefficient on PCTMFG is negative but not significant in 1970, 1980, and 1990 and positive but not significant in 2000. The coefficient on PCTSER is positive and not significant in 1970, negative but not significant in 1980, and positive and not significant in 1990 and 2000. Overall, the results on these two industry structure variables are inconsistent from one decade to the next; but their inclusion does provide some explanatory power and allows for some control for differences in industrial structure when estimating the other coefficients in the model.

The results on the regional dummies show the shifting pattern of regional performance over time. As noted earlier all the estimated coefficients on the regional dummies for 1950 are positive; and the coefficients for DME, DGL, DP, and DFW test significant at the .10 level or above. This result identified the depressed level of RPCPI of the states in the New England BEA region in 1950 relative to the states in all the other BEA regions. By 1990 six of the seven regional dummies had negative coefficients, and only the coefficient for the Middle-East BEA region had a positive sign. This same pattern held for the 2000 results as well. The states in the New England BEA region had changed their relative position on RPCPI, ceteris paribus, versus all the other planning regions versus the 1950 results except the states of the Middle-East BEA region, and the remaining difference between these two regions was not significant in 1990 or 2000. The largest negative coefficient on the regional dummies was estimated for DSW (the SouthWest BEA region) in 1960, 1970, 1980, and 2000. The South-West BEA region had the second largest estimated negative coefficient in 1990. The estimated coefficients for DRM (the Rocky Mountain BEA region) were also negative and large in each estimate 
between 1960 and 2000. These two regions had the lowest RPCPI levels over this period (1960 - 2000), ceteris paribus, versus the other six BEA regions. The BEA regions with the highest RPCPI as indicated by the positive sign and size of their estimated coefficients were the Far West states in 1950, 1970, and 1980; the Great Lakes states in 1960; and the Middle-East states in 1990 and 2000.

There is one additional result from the six decennial regressions that directly addresses the issue of convergence of state RPCPI over the 50-year period from 1950 to 2000. Appendix Table A-2 shows the coefficient of variation for each census year. The coefficient of variation measures the standard deviation of state RPCPI levels versus the mean RPCPI level for all states in percentage terms. This measure declines steadily from 22.24 percent in 1950 to 15.27 percent by 1980 and then levels off at about this same level in 1990 (15.76 percent) and 2000 (15.58 percent). This result is consistent with the findings of Vorha (1997), Mallick (1993), and Bound and Johnson (1992).

One additional regression was run adjusting the model specification and pooling the 298 observations from the six census years. The pooled data set has the advantages that RPCPI is already in constant year 2000 dollars and the quantitative independent variables in the model are all in percentage terms. The adjustment to the model was to add a set of dummy variables to the model that reflect the census years. These variables allow for measurement of fixed time effects that can reasonably be expected to exist when the six cross-sectional data sets are combined. The model for the pooled data set was thus specified as:

$$
\begin{aligned}
& \text { RPCPI }_{\mathrm{i}}=\text { B }_{0}+\mathrm{B}_{1} \text { PCTBLACK }_{\mathrm{i}}+\mathrm{B}_{2} \text { PCTURBAN }_{\mathrm{i}}+\mathrm{B}_{3} \mathrm{PCTHS}_{\mathrm{i}}+\mathrm{B}_{4} \mathrm{PCTCOL}_{\mathrm{i}} \\
& +\mathrm{B}_{5} \mathrm{PCTMFG}_{\mathrm{i}}+\mathrm{B}_{6} \mathrm{PCTSER}_{\mathrm{i}}+\mathrm{B}_{7} \mathrm{DME}_{\mathrm{i}}+\mathrm{B}_{8} \mathrm{DGL}_{\mathrm{i}}+\mathrm{B}_{9} \mathrm{DP}_{\mathrm{i}}+\mathrm{B}_{10} \mathrm{DSE}_{\mathrm{i}}+\mathrm{B}_{11} \mathrm{DSW}_{\mathrm{i}} \\
& +\mathrm{B}_{12} \mathrm{DRM}_{\mathrm{i}}+\mathrm{B}_{13} \mathrm{DFW}_{\mathrm{i}}+\mathrm{B}_{14} \mathrm{DC}_{\mathrm{i}}+\mathrm{B}_{15} \mathrm{DC}_{\mathrm{i}}+\mathrm{B}_{16} \mathrm{DC}_{\mathrm{i}}+\mathrm{B}_{17} \mathrm{DC}_{\mathrm{i}} \\
& +\mathrm{B}_{18} \mathrm{DCO0}_{\mathrm{i}}+\mathrm{E}_{\mathrm{i}}
\end{aligned}
$$

Where the new variables were specified as:

$\mathrm{DC} 0_{\mathrm{i}}=$ a dummy variable with a value of 1 for observations in census year 1960 and 0 otherwise;

$\mathrm{DC} 0_{\mathrm{i}}=$ a dummy variable with a value of 1 for observations in census year 1970 and 0 otherwise;

$\mathrm{DC} 0_{\mathrm{i}}=$ a dummy variable with a value of 1 for observations in census year 1980 and 0 otherwise;

DC90 $_{\mathrm{i}}=$ a dummy variable with a value of 1 for observations in census year 1990 and 0 otherwise; 
$\mathrm{DC} \mathrm{O}_{\mathrm{i}}=$ a dummy variable with a value of 1 for observations in census year 2000 and 0 otherwise.

Table 2 presents the OLS results for the pooled data set. The $\mathrm{R}^{2}$ value is .910 , and the F-statistic is 56.589. Only two of the six coefficients on the demographic, human capital, and industrial structure variables test statistically significant at the .10 level or above. The coefficients for PCTBLACK, PCTURBAN, and PCTHS are small, positive, and not significant. The lack of significance for PCTURBAN is somewhat surprising since this coefficient was positive in all six census year equations and significant in four of these six equations. For the pooled model, the coefficient for PCTCOL is large, positive, and statistically significant. This result is certainly consistent with the crosssectional results for 1960,1970, 1980, 1990, and 2000. College education is an important factor in explaining differences in state RPCPI across states and across time. For the pooled model the coefficient on PCTMFG is negative, small, and not statistically significant. The coefficient on PCTSER is positive and statistically significant. For the pooled model, five of the six regional dummy variables in the model have coefficients that test statistically significant, and the pattern of these results is generally consistent with the cross-sectional results reported earlier. All five of the coefficients on the dummy variables for the census years test significant. The overall results on the six coefficients on the demographic, human capital, and industrial structure variables are consistent with the cross-sectional results; and the statistical significance of eleven of twelve coefficients on the dummy variables in the model confirms the importance of controlling for fixed regional and fixed time effects.

\section{SUMMARY AND CONCLUSIONS}

The purpose of this paper was to identify factors that explain the differences in state performance levels and to examine the question of how these factor's influences have changed over time. The study used real per capita personal income (RPCPI) to measure economic performance at the state level. The model specified for this study explains state RPCPI levels as a function of a set of demographic, human capital, industrial structure, and regional dummy variables. Real per capita personal income was used as the dependent variable to allow for more direct comparisons of the magnitude of coefficients on the independent variables across census years. The choice of year 2000 dollars was made to allow the most current frame of reference for the reader in understanding the magnitudes of the estimated coefficients and to be able to better understand how these coefficients may have changed over time. The results cover the census years between 1950 and 2000 and utilized state-level decennial census information to address the research questions.

The influence of the percentage of state population classified as African American, PCTBLACK, on state RPCPI levels, measured by the regression coefficient, was negative and insignificant in 1950, 1960, 1970, and 1990 and positive but insignificant in 1980 and 2000. The coefficient on the pooled results for this variable was small, positive, and insignificant. These results suggest that, ceteris paribus, PCTBLACK's influence 
TABLE 2

State Real Per Capita Income Pooled Equation (1950 - 2000) LS // Dependent Variable is RPCPIPOOLED Included observations: 298

\begin{tabular}{lcccc}
\hline \multicolumn{1}{c}{ Variable } & Coefficient & Std. Error & t-Statistic & Prob. \\
\hline CONSTANT & 7213.937 & 1160.328 & 6.2172 & 0 \\
PCTBLACK & 15.8007 & 20.0172 & 0.7894 & 0.4306 \\
PCTURBAN & 0.1509 & 0.2025 & 0.7457 & 0.4565 \\
PCTHS & 51.4411 & 50.3967 & 1.0207 & 0.3083 \\
PCTCOL & 341.6263 & 53.3590 & 6.4024 & 0 \\
PCTMFG & -12.9451 & 46.6598 & -0.2774 & 0.7817 \\
PCTSER & 293.2497 & 65.2673 & 4.4931 & 0 \\
DME & 1703.74 & 516.497 & 3.2986 & 0.0011 \\
DGL & 542.2834 & 490.4329 & 1.1057 & 0.2698 \\
DP & -1622.715 & 504.2135 & -3.2183 & 0.0014 \\
DSE & -2883.429 & 615.3031 & -4.6861 & 0 \\
DSW & -2305.945 & 627.0137 & -3.6777 & 0.0003 \\
DRM & -2017.913 & 590.2491 & -3.4187 & 0.0007 \\
DFW & 1296.191 & 533.6163 & 2.4290 & 0.0158 \\
DC60 & 1641.128 & 392.4046 & 4.1822 & 0 \\
DC70 & 5293.043 & 496.1277 & 10.66871 & 0 \\
DC80 & 6184.841 & 747.0565 & 8.27895 & 0 \\
DC90 & 10230.51 & 805.7841 & 12.69634 & 0 \\
DC00 & 4934.791 & 973.5757 & 5.06873 & 0 \\
& & & & 17699.59 \\
\hline R-squared & 0.909914 & Mean dependent var. & 5877.722 \\
Adjusted R-squared & 0.904102 & S.D. dependent var. & 156.5587 \\
S.E. of regression & 1820.173 & F-statistic & & 0 \\
Sum squared residuals & $9.24 \mathrm{E}+08$ & Prob. (F-statistic) & \\
\hline & & & & \\
\hline
\end{tabular}

was not a factor in explaining differences in state RPCPI. This neutral result is different than the negative impact reported earlier by Izraeli and Murphy (1997) but may be consistent with Sowell's (2000) analysis since the estimated coefficients, though not significant, are initially negative and then become positive.

The estimated coefficient on the variable measuring the percent of the population of state that was classified urban (PCTURBAN) is positive, as expected, in each equation and statistically significant in four of the six cross-sectional equations. Additionally, the magnitude of the coefficient of PCTURBAN increases over time when measured against RPCPI. This overall result is consistent with the expectation that urban areas offer a wider range of educational and job opportunities as well as agglomeration effects. Therefore, states with higher concentrations of urban populations typically have higher RPCPI 
levels. The coefficient on the pooled results for this variable was positive but not significant.

The variables for education, PCTHS and PCTCOL, were included as measures of human capital and were expected to have positive coefficients. The inclusion of both variables helped address the issue of the relative importance of higher education versus a standard high school education in explaining differences in state RPCPI levels. The coefficient on PCTHS is positive but not significant in all but one census year equation. (The coefficient on PCTHS was positive and significant in 1980.) The coefficient on the pooled results for PCTHS was positive but not significant. These results suggest that while positive, the impact of differences in PCTHS on state RPCPI are at best modest. The results on PCTCOL suggest that higher education in the form of a four-year college degree has played an important positive role in explaining differences in state RPCPI levels. The estimated coefficients on PCTCOL are positive and statistically significant for each census year equation and for the pooled results. The results show that for 1960, 1970, 1990, and 2000, the impact of a one percent increase in PCTCOL increased state RPCPI by at least $\$ 1050$ or more. (In 1980 the estimate on this coefficient was $\$ 891$.) This result convincingly shows the importance of higher education in explaining state RPCPI levels over the full period of study.

The results of the influence of differences in industrial structure, measured by PCTMFG, on the state RPCPI levels are inconsistent from one decade to the next. The coefficients on this variable were positive in 1950, 1960, 1970, and 2000 and negative for 1980, 1990, and for the pooled results. None of these estimated coefficients tested significant. The coefficients for PCTSER were positive for all the census year equations and for the pooled results. Coefficients on PCTSER tested significant only in 1950 and in the pooled results.

The results on the regional dummies show the shifting pattern of regional performance over time. All the estimated coefficients on the regional dummies for 1950 are positive; and the coefficients for DME, DGL, DP, and DFW test significant. This result identified the depressed level of RPCPI of the states in the New England BEA region in 1950 relative to the states in all the other BEA regions. By 1990, six of the seven regional dummies had negative coefficients, and only the coefficient for the Middle-East BEA region had a positive sign. This same pattern held for the 2000 results as well. The states in the New England BEA region had changed their relative position on RPCPI, ceteris paribus, versus all the other planning regions versus the 1950 results except the states of the Middle-East BEA region, and the remaining difference between these two regions was not significant in 1990 or 2000.

Overall the results are encouraging as the models produced $\mathrm{R}^{2}$ values that ranged from .749 (in 1980) to .888 (in 1960). The results suggest that the racial composition of state populations has had little influence on state RPCPI levels. The important variables in explaining RPCPI differences between the states appear to be the percentage of the population that lives in urban areas, the percentage of the population with a four-year 
college degree, and the percentage of the population employed in the service sector. Finally, the results are also consistent with the convergence then leveling-off of state PCPI levels found in earlier studies.

\section{REFERENCES}

Barro, R.J. and X. Sala-i-Martin, 1992. “Convergence,” Journal of Political Economy 100(2), 223-251.

Berry, D.M. and D.L. Kaserman. 1993. "A Diffusion Model of Long-Run State Economic Development," Atlantic Economic Journal 21(4), 39-54.

Bound, J. and G. Johnson, 1992. "Changes in the Structure of Wages in the 1980s: An Evaluation of Alternative Explanations,” American Economic Review 82, 371-92.

Garnick, D.H., 1990. "Accounting for Regional Differences in Per Capita Personal Income Growth: An Update and Extension,” Survey of Current Business 70(1), 29-40.

Izraeli, O. and K. Murphy, 1997. "Convergence in State and Real Per Capita Income: Empirical Evidence,” Public Finance Review 25, 555-577.

Levernier, W., Partridge, M.D., and D.S. Rickman, 1995. "Variation in State Income Inequality: 1960-1990,” International Regional Science Review 18(3), 355-378.

Mallick, R., 1993. "Convergence of State Per Capita Incomes: An Examination of its Sources," Growth and Change 24(3), 321-340.

Nissan, E. and G.H. Carter, 2003. "Contributions of States to Regional Income Dispersion," Journal of Economics and Finance 27, 243-261.

Sowell, T., 2000. “Census Facts Shatter Leftists' Beliefs,” Human Events 56(48), 18-19.

U.S. Department of Labor, Bureau of the Census, 1950, 1960, 1970, 1980, 1990, 2000. Census of Population. U.S. Government Printing Office: Washington, D.C.

Vohra, R., 1997. "An Empirical Investigation of Forces Influencing Productivity and the Rate of Convergence Among States,” Atlantic Economic Journal 25(4), 412-419.

\section{APPENDIX}

Table A-1

States and BEA Regions

\begin{tabular}{ccc}
\hline State or Region Code & State or Region Name & Region Code \\
\hline 91 & New England Region & 1 \\
09 & Connecticut & 1 \\
23 & Maine & 1 \\
25 & Massachusetts & 1 \\
33 & New Hampshire & 1 \\
44 & Rhode Island & 1 \\
50 & Vermont & 1 \\
\hline 92 & Mideast Region & 2 \\
10 & Delaware & 2 \\
11 & District of Columbia & 2 \\
24 & Maryland & 2 \\
34 & New Jersey & 2 \\
36 & New York & 2 \\
42 & Pennsylvania & 2 \\
\hline
\end{tabular}




\begin{tabular}{|c|c|c|}
\hline State or Region Code & State or Region Name & Region Code \\
\hline 93 & Great Lakes Region & 3 \\
\hline 17 & Illinois & 3 \\
\hline 18 & Indiana & 3 \\
\hline 26 & Michigan & 3 \\
\hline 39 & Ohio & 3 \\
\hline 55 & Wisconsin & 3 \\
\hline 94 & Plains Region & 4 \\
\hline 19 & Iowa & 4 \\
\hline 20 & Kansas & 4 \\
\hline 27 & Minnesota & 4 \\
\hline 29 & Missouri & 4 \\
\hline 31 & Nebraska & 4 \\
\hline 38 & North Dakota & 4 \\
\hline 46 & South Dakota & 4 \\
\hline 95 & Southeast Region & 5 \\
\hline 01 & Alabama & 5 \\
\hline 05 & Arkansas & 5 \\
\hline 12 & Florida & 5 \\
\hline 13 & Georgia & 5 \\
\hline 21 & Kentucky & 5 \\
\hline 22 & Louisiana & 5 \\
\hline 28 & Mississippi & 5 \\
\hline 37 & North Carolina & 5 \\
\hline 45 & South Carolina & 5 \\
\hline 47 & Tennessee & 5 \\
\hline 51 & Virginia & 5 \\
\hline 54 & West Virginia & 5 \\
\hline 96 & Southwest Region & 6 \\
\hline 04 & Arizona & 6 \\
\hline 35 & New Mexico & 6 \\
\hline 40 & Oklahoma & 6 \\
\hline 48 & Texas & 6 \\
\hline 97 & Rocky Mountain & 7 \\
\hline 08 & Region & 7 \\
\hline 16 & Colorado & 7 \\
\hline 30 & Idaho & 7 \\
\hline 49 & Montana & 7 \\
\hline 56 & $\begin{array}{c}\text { Utah } \\
\text { Wyoming }\end{array}$ & 7 \\
\hline 98 & Far West Region & 8 \\
\hline 02 & Alaska & 8 \\
\hline 06 & California & 8 \\
\hline 15 & Hawaii & 8 \\
\hline 32 & Nevada & 8 \\
\hline 41 & Oregon & 8 \\
\hline 53 & Washington & 8 \\
\hline
\end{tabular}


Table A-2

White Heteroskedasticity Test Results

\begin{tabular}{cccc}
\hline Regression & $\mathrm{N}$ & $\mathrm{k}$ & Test-statistic \\
\hline 1950 & 48 & 20 & $1.605116^{* *}$ \\
1960 & 50 & 20 & 6.019424 \\
1970 & 50 & 20 & 3.055134 \\
1980 & 50 & 20 & $2.090255^{*}$ \\
1990 & 50 & 20 & $1.189388^{* *}$ \\
2000 & 50 & 20 & $2.061277^{*}$ \\
\hline
\end{tabular}

* accept Ho: at the .01 level

** accept Ho: at the .05 level

White's test for heteroskedasticity tests the null hypothesis that the errors are both homoskedastic and independent of the regressors and that the linear specification of the model is correct. Failure of any one or more of these conditions could lead to a significant test statistic. Conversely, a non-significant test statistic would be very reassuring since it implies that none of the three conditions is violated. The t-statistics in Table 1 reflect robust errors based on White's correction for heteroskedasticity for 1960, 1970, 1980, and 2000.

Table A-3

RPCPI Elasticities ${ }^{\mathrm{a}}$ by Census Year: 1950 Thru 2000

\begin{tabular}{lcccccl}
\hline & \multicolumn{7}{c}{ Census } & Year \\
Variable & 1950 & 1960 & 1970 & 1980 & 1990 & 2000 \\
\hline PCTBLACK & -0.317 & -0.147 & -0.181 & 0.196 & -0.029 & 0.048 \\
PCTURBAN & $0.332^{*}$ & 0.085 & $0.263^{*}$ & 0.199 & $0.375^{*}$ & $0.407^{*}$ \\
PCTHS & 0.361 & 0.046 & 0.046 & $1.507^{*}$ & 0.695 & 0.267 \\
PCTCOL & 0.638 & $11.359^{*}$ & $6.116^{*}$ & $4.357^{*}$ & $4.490^{*}$ & $4.140^{*}$ \\
PCTMFG & 1.175 & $1.178^{*}$ & $0.226^{*}$ & -0.573 & -0.189 & 0.461 \\
PCTSER & $5.663^{*}$ & 0.395 & 0.579 & 0.340 & 0.807 & 0.580 \\
$\mathrm{R}^{2}$ & 0.874 & 0.888 & 0.850 & 0.749 & 0.869 & 0.816 \\
\hline
\end{tabular}

a. All elasticities calculated at the point of means.

* Asterisks indicate elasticities calculated with coefficients that tested significant at the 0.10 level using two-tailed tests.

Table A-4

Coefficient of Variation by Census Year: 1950 Thru 2000

\begin{tabular}{|c|c|c|c|c|c|c|}
\hline & \multicolumn{6}{|c|}{ Census Year } \\
\hline & 1950 & 1960 & 1970 & 1980 & 1990 & 2000 \\
\hline $\begin{array}{l}\text { Coefficient of } \\
\text { Variation }^{\mathbf{a}}\end{array}$ & $22.24 \%$ & $19.66 \%$ & $16.52 \%$ & $15.27 \%$ & $15.76 \%$ & $15.57 \%$ \\
\hline
\end{tabular}

